\title{
Land Subsidence Caused by Urban Metro Tunnel Construction
}

\author{
Yang Hao*
}

The Second Department Company Limited of China Railway Tunnel Group, Qingdao, Shandong, 266000, China

\begin{abstract}
S With the development of urban transportation, city buses are unable to accommodate daily ground transportation for the public in life, work and study; therefore, urban metro gains rapid development. However, metro tunnel construction would initiate land subsidence issues which bring significant potential safety hazards and economic losses. In order to reduce irrelevant economic losses, this paper discusses the land subsidence issues from three perspectives: analysis of land subsidence, land subsidence safety judgment and control and shallow tunnel excavation method in tunnel construction used to control land subsidence. The paper indicates that there are major geotechnical engineering issues encountered during urban metro tunnel excavation process. The individuals in charge of implementation should optimize tunnel construction regulations and ensure all works are implemented scientifically, regularly and orderly in order to reduce the impacts on land subsidence caused by tunnel construction.
\end{abstract}

\section{KEYWORDS}

Urban metro

Tunnel construction

Land subsidence

\section{Introduction}

With rapid economy development, the areas of lands for public to do ground activities was narrower day by day, especially after the emergence of large scaled cities. The availability of land usage is decreasing. In order to meet public transportation demands, the land transportation network starts operating underground which facilitate the development of metro tunnel. To ensure a stable development of metro, we need to have effective prevention of damages caused by land subsidence.

\section{Analysis of Land Subsidence}

Prior to metro tunnel excavation, we need to analyze the land subsidence problems caused by metro tunnel.

During the metro tunnel excavation process, the construction causes a great impacts on surrounding soil layers as well as on environment. Land subsidence could lead to

\section{Copyright $\odot 2015$ Yang Hao}

doi: $10.18686 /$ utc.v2i1.7

Received: October 11, 2015; Accepted: October 29, 2015; Published online: December 2, 2015

This is an open-access article distributed under the terms of the Creative Commons Attribution Unported License (http://creativecommons.org/ licenses/by-nc/4.0/), which permits unrestricted use, distribution, and reproduction in any medium, provided the original work is properly cited.

${ }^{*}$ Corresponding author: The Second Department Company Limited of China Railway Tunnel Group, Qingdao, Shandong, 266000, China. Email: haoyang_1234@sina.com serious consequences; it could cause economic losses because of various pipelines would fall apart; It is necessary to either change the routes of those pipelines or reinforce them during tunnel excavation.

If there are bridges on the ground during tunnel excavation works, the bridge foundation may subsidence or the backbone of the bridge could be damaged irreversibly. For serious cases, the bridges may collapse that account to enormous economic losses.

The land subsidence will cause huge damage to buildings on the ground. The damages to house architectural structures are as follows:

(1) Land subsidence will have impacts on building foundations. When the metro tunnel excavation starts, it will generate both horizontal forces and vertical forces. The structure of buildings could only bear vertical forces instead of horizontal forces. Therefore, the major damaging forces are horizontal forces when the foundation was damages.

(2) The land subsidence will reduce the bearing capacity of building's foundation. The heading end will loosen the soil layers continuously during tunnel excavation. The soil layer becomes loose; the bearing capacity of building's foundation will decrease. Therefore, it is necessary to reduce the vibration to the soils during construction.

(3) Land subsidence will bring irreversible damages to building's superstructure. The underground construction will generate forces on buildings on the ground. The forces 
are irregular and causes unbalanced shape changes to the complete buildings and make the buildings lost its center of gravity and collapse eventually [1].

Most cities build metro tunnel constructions. The expert's states that it was common for the buildings to collapse due to tunnel construction. Those accidents have drawn attentions from relevant departments and the society. With years of research and study, we have made achievements and establish theory till today. However, China does not have comprehensive safety regulations to various buildings. Our research aims to reinforce those buildings according to the allowed max value of land subsidence. We have to implement this method even it is inappropriate scientific, inaccurate and lack of support theory. The purpose of this method is to prevent accidents and unnecessary economic losses. In real situations, certain buildings are not sensitive to land subsidence. However, the construction company still reinforce those buildings and it is a waste of investments. We need to analyze actual scenarios based on experience and specific construction conditions as to save costs.

\section{Safety Judgment of Land Subsidence and Control}

The soils characteristics are diverse in different cities. The buried depths of tunnel are different as well, especially with consideration of the buildings' various bearing capacities. Those factors will influence the safety judgments of land subsidence completely. Various safety factors should be taken into consideration including buildings on the ground and tunnels underground before compute the final construction plan. According to previous domestic metro construction experiences, the surface deformation in construction should be monitored within the range of $+10 \sim$ $-30 \mathrm{~mm}$.

There are certain principles to restraint from the land subsidence. Use all measures to maintain the stability of soils surrounding rocks; reduce water and soil loss and to control land subsidence. The construction designing staffs shall implement different measurement at different soil subsidence stages according to actual construction conditions to control land subsidence, e.g., the most frequently use shield method. During tunnel construction, buildings (constructions) on the ground, underground pipelines, soil layer and soil layers' structures should take full consideration to control land subsidence. Ensure the water and soil loss is within the allowed range in order to take the minimum allowed value as standard. We could set pre-warning value, warning values and limit values to do controls at different levels during construction.

\section{Shallow Tunneling Excavation Method in Tunnel Construction to Control Land Subsidence}

The measures should be taken in the way of excavation, forepoling protection and discharge of underground water to reduce the land subsidence from every session and to control the land subsidence is within the allowed range.

\subsection{Way of Excavation}

The soil textures are different at different soil layers. Location of the excavation should be determined according to the soil layers. The distance between excavation surfaces should be from 3 to 5 meters. To reduce the exposure time of soil in air, the forepoling protection should be done in time. Prior to excavation, it need to do grouting reinforcement to the tunnel face and according to the specific conditions of the site to adjust pipeline, grid protection and other parameters to ensure the effectiveness of grouting as well as improve the stability of the soil to the most. As to the excavation of fracture surface, it should use manual excavation approach to avoid unnecessary excavation and to reduce the footstep distance, that is the number of areas that was dug and areas are forepoling protected [2].

\subsection{Improve Soil's Characteristics}

During the excavation process, the soil around the tunnel should be done with partial reinforcement treatment. This could facilitate the formation of natural arch after excavation and improve the soil's characteristics to a degree that allow the soil to develop towards sound direction, for instance, pre-grouting and deep layer grouting could both reinforce the soil and improve soil's characteristics.

\subsection{Discharge of Underground Water}

Typically, the fracture surface is at lower position during excavation process, the underground water may permeate the excavation surface. However, we unable to drain water as it would lead to over consolidation to special soil layers. The large areas of those soil layers will sink. The discharge of underground water shall be in accordance with requirements.

\subsection{Grid Spray Supporting Protection}

If use grid sprays support to do protection, it requires to pay attention to node locations installation including ensure the grid joint meets the requirements of welded conjunction. Besides following the requirements to do installation, it also required to ensure the bolts are tight. The anchors of every grid shall be strictly built and do grouting. Before spray the concrete, construction workers should clean the water and sludge to make the operating surface clean in order to ensure the foundation able to accommodate sufficient bearing capacity. Moreover, it also needs to pre-bury the pipelines of secondary grouting as the preparation of further construction.

\subsection{Preliminary Backbone Anchor Spray Supporting Protection}

According to the actual land subsidence and leakage situation, usage of the pre-buried secondary grouting pipelines to do supplementary grouting operation. If water is 
not available, alternatively M100 cement should be used. If there is water, it should be use in the mixture of cement and sodium silicate to do grouting. The proportion could be adjusted based on the condition of the spot but the grouting pressure should not be higher than $0.5 \mathrm{MPa}$. The amount of grouting shall be determined according to the actual condition on spot [3].

\subsection{Demolition of Temporary Supporting Protection}

If there are temporary supporting protections, when need to demolish them, demolition should be strictly done when the tunnel is stable after the tunnel changed shape. The demolition could not carried out continuously. It should be done with gaps between them or use second demolition.

\section{Conclusion}

Along with state economy development, the metro tunnel develops drastically. There are major geotechnical engineering issues encountered during tunnel excavation. To resolve those issues effectively, the persons in charge of implementation should optimize tunnel construction regulations and ensure all works are implemented scientifically, regularly and orderly in manner as to reduce the impacts on land subsidence caused by tunnel construction.

\section{References}

1. Miu, L. C., Wang, F. \& Lv, W. H. (2008). Land Subsidence caused by Urban Metro Construction. Southeast University Newspaper (Nature Colume) ISTIC EI PKU, 2, 36-39.

2. Fu, G. (2013). Shallow Buried Excavation of Metro Tunnel to Control Land Subsidence. Scientific and Technological Information, 8, 57-61.

3. Zhong, J. (2013). Analysis of Land Subsidence in Guangzhou Subway Line 6 Shield Tunnel Construction. Study of Urban Construction Theory, 15, 158-159. 